\title{
THE SMART CITY AS A SOCIAL POLICY ACTOR
}

\author{
Diogo Miguel Mendes Correia ${ }^{1}$ and José Eduardo Silva Abreu Lopes Feio ${ }^{2}$ \\ ${ }^{I}$ Department of Economics, Management, Industrial Engineering and Tourism (DEGEIT) \\ University of Aveiro, Portugal \\ ${ }^{2}$ Department of Social Policy and Intervention, University of Oxford, United Kingdom
}

\begin{abstract}
Smart City literature has started focusing on new technologies that are being developed to improve cities' inner processes. Nowadays, it moved into considerations of the role of citizens in these improvements and ways to adapt new technologies to fit their needs. Smart Cities are, therefore expanding. It can be noted both in numbers and in scope. For the former, investment and interest in the topic has been growing as more and more cities aim to be considered "smart". For the latter, with more and more technological developments, the possibilities for the areas in which cities can be "smart" has increased. This has led to Smart Cities increase in the scope of action. Social participation and inclusion are taken in consideration, creating the Smart Inclusive City. Moreover, this article argues that Smart Cities are emerging as new social policy actors. Concepts from the social policy literature such as welfare regimes, intersectionality, and gender mainstreaming become relevant to Smart City scholars.
\end{abstract}

\section{KEYWORDS}

“Smart Inclusive Cities”, “Social Policy”, “Citizens”, "Inclusion”, "Intersectionality”, "Welfare Regimes”

\section{INTRODUCTION}

Smart Cities, and especially Smart Cities technologies, are seen as the solution to create new ways to solve these emerging problems such as urban pressure, air pollution, congestion, waste management, and human health (Ahvenniemi et al., 2017). However, it is difficult to find ways to finance a Smart City initiative if it is not possible to monetize its benefits, which happens, for example, in social impact projects. Which lead them not to be a priority to policymakers. There are huge disparities within cities. While some authors discuss for how long we will continue living without the autonomous vehicles, there are still cities that are not even coherent in obliging buildings to have access for disabled people.

Nowadays, we are witnessed a change in how decision-makers include citizens in the co-creation and co-designing processes. We are in the Smart Cities 3.0 stage (Cohen, 2015). Smart Cities are more and more seen as cities for people, created and designed with the citizens instead of focusing on the technological approach. However, we must ensure that all voices are heard, not letting the most needed out of the equation.

A real change in paradigm is still to come, and the literature on Smart Cities still lags. In the next chapters, it is argued that in the next phase of its development, the concept of Smart Cities should embrace the language of inclusion. Moreover, elements of the literature of social policy that can inform this move are outlined.

\section{TIME OF CHANGING THE PARADIGM}

The latest technological advances in the field of Information and Communication Technology (ICTs) supporting a citizen-centric urban development for cities can have a tremendous effect on future cities. ICTs can be a fundamental help to cities in every stage: in diagnosing problems, devising solutions, and the analysing results.

After Hollands (Hollands, 2008) criticized the fact that the focus should not be on the technological side, the concept evolved from the technical point of view and has been hardly discussed. Technological companies were the ones to push for innovation and the quick implementation of solutions. These were most of the times 
not prepared to install in the urban furniture. Cities started to understand the benefits of implementing ICTs to gather real time data to increase the awareness of the cities' problems and act quickly. During the last years, the focus changed from the technology and economy, where the citizens were had a passive role to a focus on people, governance, and policy where citizens act as co-creators and contributors for the citizen (Trencher, 2019). We are now in the time of the "Smart City 3.0" (Cohen, 2015), where citizens now have an active roll in the establishment of the strategy and associated policies. Smart Cities are now seen as the final stage of urban development, representing a conceptual urban development model, using human, collective and technological capital (Angelidou, 2015), where the adoption of technology is not an end. Still, a more vital thing is the management and policies behind the use of the technology (Nam and Pardo, 2011).

\section{SMART INCLUSIVE CITY}

Smart Cities face the challenge of dealing with the issue of widening inequality and social polarization (Hollands, 2008). Special attention has started to be noted in the literature of having policies that shall promote the inclusion of citizens in cities by including them in the process of decision making as one of the interested parties (Oliveira, 2015).

Cities of the future are seen as sustainable cities where all residents (with no exception) live well and the attraction of cities is preserved (Thuzar, 2011). Cities will have to provide conditions for a healthy and happy community under the challenging conditions that global, environmental, economic and social trends may bring. Cities encompass an efficient, technologically advanced, sustainable, and socially inclusive city (Pereira et al., 2017).

Smart Inclusive City is a city that puts innovation available and working to everyone and whose policies are made with and to improve the quality of life of every citizen, not letting aside the disadvantaged. Moreover, it is a city whose aim is to reduce social learning restrictions and social participation barriers (Silva, Khan and Han, 2018).

The role of citizens in Smart Cities, passed from a passive role to one where they are seen as a "source of data". Nowadays, they are much more than that, and citizens now understand that it does not make sense to build a city without including the main stakeholder in the equation (Healey and Gonza, 2005; Cossetta and Palumbo, 2016), helping on the planning and design (Cowley et al., 2018; Sadoway and Univerisity, 2018). Moreover social innovation can be understood as a 'design- by-doing' process (Brown et al., 2012). Citizens are more and more the center of cities. However, cities of today are not seen as inclusive as they should be since there still a lot to do in this matter to accomplish the basic needs of every citizen, as identified above.

Smart Cities must consider a global vision to develop and implement a set of policy-mechanisms through an alternative institutional governance model to change this scenario (Lee, Hancock and $\mathrm{Hu}, 2014$ ). Inclusion is something that should be promoted by city policymakers. A City can no longer be smart without being inclusive.

Therefore, several points must be taken into account by cities. First, cities must incentive companies to develop technologies to everyone or dedicated to solving a specific problem dictated by citizens. Second, cities must consider previously implemented technologies and best-practices and make the match between these and the needs of the city.

\section{SMART CITIES AS SOCIAL POLICY ACTORS}

We argue that Smart Cities have the potential to be social policy actors that embrace inclusivity at the foreground of its agenda. This changing in the way one conceptualises Smart Cities will lead to two main consequences. First, a whole set of areas of action will be open for Smart Cities. In other words, changing how we conceptualise Smart Cities will enable us to ask different questions about what they can and should do. Second, changing conceptualisations will open a whole tool kit of concepts that have been developed in the social policy literature, which can be now served Smart City scholars.

Changing conceptualisations are often implicit in policy actors (Bacchi and Goodwin, 2016). These happen as practitioners realise via lived experience that the potential for a concept to evolve exists in practice. When it comes to conceptualising Smart Cities as social policy actors, this can be noted in local authorities' work in various cities such as Vienna, Rio de Janeiro, Ljubljana and London. 
Over the past few decades, Vienna has integrated gender considerations into how they plan the development of the urban space. For example, through evaluating commuting patterns, it was made clear that women and girls use footways more than men, who tend to reduce more using vehicles. The city then used this knowledge to invest in public lightning in areas used predominantly by women and girls (Vienna, 2019). In the same line of investment, in Rio de Janeiro, local authorities have used technologies such as Safetipin to gather data on violence and harassment against women and girls. (Women, 2013). Women and girls are then able to record the areas of the city where they feel less safe. This has allowed local authorities to shape their urban development towards addressing these specific areas of the city.

The capital of Slovenia, Ljubljana, has implemented a solution for its citizens by providing electric vehicles that are available for everyone to request them by phone or online, to take them from home to the city center (Wedam, 2019).

Homelessness in London is a significant problem as the number of people living in the street has been rising for the past few years. To address this, the Mayor of London has put contactless points across the city to people donate money to various NGOs and created a GoFundMe page. Through this, they were able to raise more than $£ 74.000$ in less than two weeks (London, 2018).

The above can be seen as evidence for greater care from local authorities towards implementing various technologies to improve the inclusion of their cities. This is often not done as an explicit change in the way Smart Cities are understood but rather as an implicit change in goals. A policy change of this type is referred to in the literature as social learning (Bennett and Howlett, 1992). This can involve changes in "the social construction of policy problems, the scope of the policy, or policy goal" (May, 1992). What the examples above show is a shift in the policy goals of these cities. These cities are changing the purposes for which they use technologies towards the promotion of inclusion. In this way, we argue that even if implicitly, they are conceptualizing Smart Cities as social policy actors. This is, actors concerned with promoting inclusion and social wellbeing of their populations through the use of technologies.

How one conceptualises policy issues and policy actors change the expectations and questions asked about them (Lancaster, Duke and Ritter, 2015). In the early 20th century, changing conceptualisations about the role of the state led to changes in expectations towards (Castles, 2012). Foucault called bio-politics to the development of ways in which the state has become concerned with wellbeing and the life of its citizens (Nadesan, 2008). Conceptualising Smart Cities as social policy actors can be seen as a parallel transformation to this. It means seeing the goal of Smart Cities not just in terms of technologies but also the inclusivity and well-being of its citizens. It means asking different questions about the role that the technologies developed can play. For example, besides questioning how they can impact effectiveness and costs, it means asking how they affect inclusivity.

\section{WELFARE REGIME TYPES AND THE "SMART CITY 3.0"}

With a move towards a view of Smart Cities as social policy actors and an increasing attempt to include citizens and stakeholders at various levels, a whole literature from the discipline of social policy becomes relevant.

One of the pivots works in the field of social policy is that of (Esping-Andersen, 1990). Esping-Anderson (1990), divides high-income countries into three ideal types. These typical types, which he calls welfare regimes, correspond to different ways of combining the market, family, and the state in the provision of goods and services. The United Kingdom, for example, is considered as a liberal welfare regime (Wincott, 2006). Liberal welfare regimes are characterised by liberalised labour markets that lead to high levels of commodification. In other words, too high degrees of market influence on the provision of goods and services. The social democratic welfare regime is exemplified by countries such as Sweden. There are high decommodification levels and heavy reliance on the state for the provision of goods and services over the family and the market. Conservative welfare regimes type countries such as Germany and Italy are countries can be seen as in between liberal and welfare regime, with a higher reliance on family and social structures than any of the other two.

The relation between welfare regimes and specific policies is sometimes hard to discern. While some policies might follow the commodifying tendency of the welfare regime, other policies might act in a decommodifying way in order to counteract some of the undesirable trends of the welfare regime's general commodifying effect (Stephens and Fitzpatrick, 2007). Nevertheless, policy choices will always be influenced by the wider context in which they are inserted, one way or the other. When it comes to homelessness policy, Stephens and Fitzpatrick (2007) give the example of housing policy in which the UK's safety net for under 
risk homelessness people can be seen as having a decommodifying effect. This, in response to the undesirable effects of commodification in this field created by the UK's welfare regime types. However, other homelessness policies, such as the specific reliance on charities and volunteering organizations can be seen as following the welfare regime's commodifying tendency.

Any attempt to pursue more inclusive and stakeholder aware Smart Cities need to consider this wider context. If Smart Cities are to get out of their bubble, they must be mindful of what is out of it. More specifically, they must be mindful of the structures and relations between stakeholders who attempt to provide welfare to citizens and how these vary from country to country. The literature on welfare regimes can provide an entry point to this.

\section{NON-TOKENISTIC PARTICIPATION AND INTERSECTIONALITY}

Various early attempts to promote gender equality suffered from the fact that they were based on tokenistic approaches (Cornwall, 2003). In other words, programs and policies were designed including specific women, assuming that they would represent the views of other women. However, it has been realised that there is a need not to assume that one individual just because they are members of a group, such as women, will automatically represent this group. Moreover, just because someone is present that does not mean that their interests will be represented. Cornwall reviews various attempts to promote gender equality in countries of the Global South. She outlines how many of these while they aim to include women, they do so in a tokenistic way. Individual women are present, but they are often either not given the opportunity to express their interests or do not represent the interests of women more broadly. Groups such as women are not homogeneous, the struggles they face are shaped by factors beyond gender, such as income and race.

If Smart Cities should aim to be inclusive, they need not start from zero. Insights from previous failed attempts to address issues of inclusivity should be taken into consideration.

\section{CONCLUSION}

In conclusion, digitalisation inequalities will be growing in the future. Without considering inclusion, the barrier between those who are able to access the benefits of Smart Cities and those who are not will keep growing.

This article has argued that with the evolution of Smart Cities, one can start to conceptualise them as social policy actors who should care about its own inclusivity. Some of the consequences of conceptualising Smart Cities in such a way have been discussed. It has been argued that literature from social policy becomes relevant once this conceptualisation is accepted. Notions such as welfare regimes and intersectionality become suitable for scholars of Smart Cities. Smart Cities have the potential to become inclusive if they embrace citizens at all stages. Doing so will lead to better Smart Cities that genuinely fit with the needs of its people.

Aligned with the evolution of the Smart Cities concept, the methodology that a city must follow to become smart must acknowledge the role of the citizen over the several steps, and with the aim of promoting the inclusion of every citizen. There is still plenty of work to do in this field. There is more and more discussion about participatory approaches and what may be the designing tools citizens can help from. However, it is still missing KPIs focused on inclusion and a definition of an index capable of quantifying the inclusiveness in a city, guaranteeing that the promoted policies are aligned with inclusion goals.

\section{REFERENCES}

Ahvenniemi, H. et al. (2017) 'What are the differences between sustainable and smart cities?', Cities. Elsevier B.V., 60, pp. 234-245. doi: 10.1016/j.cities.2016.09.009.

Angelidou, M. (2015) 'Smart cities: A conjuncture of four forces', Cities. Elsevier Ltd, 47, pp. 95-106. doi: 10.1016/j.cities.2015.05.004.

Bacchi, C. and Goodwin, S. (2016) Poststructural policy analysis: A guide to practice.

Bennett, C. J. and Howlett, M. (1992) 'The lessons of learning: Reconciling theories of policy learning and policy change', Policy Sciences, 25(3), pp. 275-294. doi: 10.1007/BF00138786. 
Brown, T. et al. (2012) 'Design Things and Design Thinking: Contemporary Participatory Design Challenges Erling Bjögvinsson, Pelle Ehn, Per-Anders Hillgren', 28(3), pp. 101-116.

Castles, F. G. (2012) 'The Oxford handbook of the welfare state'. Oxford: Oxford University Press.

Cohen, B. (2015) No Title. Available at: https://www.fastcompany.com/3047795/the-3-generations-of-smart-cities.

Cornwall, A. (2003) 'Whose Voices? Whose Choices? Reflections on Gender and Participatory Development', 31(8), pp. 1325-1342. doi: 10.1016/S0305-750X(03)00086-X.

Cossetta, A. and Palumbo, M. (2016) 'The Co-production of Social Innovation Social innovation : The Case of Living Lab Living Lab’, (July). doi: 10.1007/978-3-319-06160-3.

Cowley, R. et al. (2018) 'The smart city and its publics : insights from across six UK cities', Urban Research \& Practice. Routledge, 11(1), pp. 53-77. doi: 10.1080/17535069.2017.1293150.

Esping-Andersen, G. (1990) 'The three worlds of welfare capitalism'. Princeton, N.J.: Princeton University Press.

Healey, P. and Gonza, S. (2005) 'A Sociological Institutionalist Approach to the Study of Innovation in Governance Capacity', 42(11), pp. 2055-2069.

Hollands, R. G. (2008) 'Will the real smart city please stand up? Intelligent, progressive or entrepreneurial?', City, 12(3), pp. 303-320. doi: 10.1080/13604810802479126.

Lancaster, K., Duke, K. and Ritter, A. (2015) 'Producing the "problem of drugs": A cross national-comparison of "recovery" discourse in two Australian and British reports', International Journal of Drug Policy. Elsevier B.V., 26(7), pp. 617-625. doi: 10.1016/j.drugpo.2015.04.006.

Lee, J. H., Hancock, M. G. and Hu, M. C. (2014) 'Towards an effective framework for building smart cities: Lessons from Seoul and San Francisco', Technological Forecasting and Social Change. Elsevier Inc., 89, pp. 80-99. doi: 10.1016/j.techfore.2013.08.033.

London, M. of (2018) Mayor's rough sleeping campaign raises over $£ 78,000$ in first fortnight. Available at: https://www.london.gov.uk/press-releases/mayoral/all-funds-going-to-vital-charities (Accessed: 18 April 2019).

May, P. J. (1992) 'Policy Learning and Failure', Journal of Public Policy, 12(4), pp. 331-354. doi: $10.1017 / \mathrm{S} 0143814$ X00005602.

Nadesan, M. H. (2008) Governmentality biopower and everyday life, Governmentality Biopower and Everyday Life. doi: $10.4324 / 9780203894620$.

Nam, T. and Pardo, T. A. (2011) 'Conceptualizing smart city with dimensions of technology, people, and institutions', in ACM International Conference Proceeding Series, pp. 282-291. doi: 10.1145/2037556.2037602.

Oliveira, Á. (2015) 'From Smart Cities to Human Smart Cities'. doi: 10.1109/HICSS.2015.281.

Pereira, G. V. et al. (2017) 'Delivering public value through open government data initiatives in a Smart City context', Information Systems Frontiers. Information Systems Frontiers, 19(2), pp. 213-229. doi: 10.1007/s10796-016-9673-7.

Sadoway, D. and Univerisity, C. (2018) '( Re ) prioritizing Citizens in Smart Cities Governance : Examples of Smart Citizenship from Urban India', 324953632(May).

Silva, B. N., Khan, M. and Han, K. (2018) 'Towards sustainable smart cities: A review of trends, architectures, components, and open challenges in smart cities', Sustainable Cities and Society. Elsevier, 38(January), pp. 697-713. doi: 10.1016/j.scs.2018.01.053.

Stephens, M. and Fitzpatrick, S. (2007) 'Welfare Regimes, Housing Systems and Homelessness: How are they Linked?', European Journal of Homelessness, 1(December), pp. 201-212.

Thuzar, M. (2011) 'Urbanization in Southeast Asia: Developing Smart Cities for the Future?', Regional Outlook, pp. 96-100. doi: 10.1355/9789814311694-022.

Trencher, G. (2019) 'Technological Forecasting \& Social Change Towards the smart city 2 . 0 : Empirical evidence of using smartness as a tool for tackling social challenges', Technological Forecasting \& Social Change. Elsevier, 142(October 2017), pp. 117-128. doi: 10.1016/j.techfore.2018.07.033.

Vienna, C. of (2019) Gender mainstreaming in Vienna.

Wedam, D. (2019) Kavalir: getting around the city centre by electric car. Available at: https://www.visitljubljana.com/en/visitors/travel-information/getting-around/kavalir-getting-around-the-city-centreby-electric-car/ (Accessed: 20 April 2019).

Wincott, D. (2006) 'Paradoxes of new labour social policy: Toward universal child care in Europe's "most liberal" welfare regime?', Social Politics, 13(2), pp. 286-312. doi: 10.1093/sp/jxj011.

Women, U. (2013) In Rio de Janeiro's favelas, a new online tool tackles violence against women and girls. Available at: http://www.unwomen.org/en/news/stories/2013/6/rio-de-janeiro-apps-to-endviolence-\%0Ain-favelas (Accessed: 17 April 2019). 